\section{SAT0521 INCREASING PHYSICAL ACTIVITY IN OLDER PEOPLE WITH PAIN. PRELIMINARY RESULTS OF THE IPOPP PILOT TRIAL}

J. McBeth ${ }^{1,2}$, E. Nicholls ${ }^{2,3}$, E. Healey ${ }^{2}$, N.E. Foster ${ }^{2,3}$, E.M. Hay ${ }^{2}$, T. Pincus ${ }^{4}$, S. Dent ${ }^{2}$, C.A. Chew-Graham ${ }^{2}$, L. Hartshorne ${ }^{3}$, C. Jinks ${ }^{2}$ on behalf of iPOPP team. ${ }^{1}$ Arthritis Research UK Centre for Epidemiology, The University of Manchester, Manchester; ${ }^{2}$ Research Institute for Primary Care and Health Sciences; ${ }^{3}$ Keele Clinical Trials Unit, Keele University, Keele; ${ }^{4}$ Department of Psychology, University of London, London, United Kingdom

Background: Chronic ( $\geq 3$ months) pain is associated with physical inactivity in older ( $\geq 65$ years) people. Walking is an acceptable form of physical activity with health benefits. We have developed Increasing Physical Activity in Older People with Pain (iPOPP), a brief intervention to increase walking.

Objectives: To assess the acceptability and credibility of iPOPP, and to test the feasibility of trial processes, in a pilot randomised controlled trial.

Methods: Eligible responders to a screening questionnaire ( $\geq 65$ years; consulted their general practitioner for chronic pain; Chronic Pain Grade score $\geq 2$ ) collected 7-day accelerometer data before randomisation and at the end of follow-up. Participants were randomised to one of Usual primary care; Pedometer, walking diary, pain toolkit (written pain management information); or iPOPP comprising week 1 face-to-face Health Care Assistant (HCA) consultation to develop a walking action plan, pedometer, walking diary, pain toolkit, discussion of walking behaviour and barriers, goal setting; week 2 follow up face-to-face or telephone (participant preferred) HCA consultation to review progress and goals, relapse prevention strategies; weeks 3-10 weekly motivational prompts (participant preferred postcard, email or text). A follow-up questionnaire was sent 12 weeks post-randomisation.

Success criteria were: $7 \%$ of those screened would be eligible, return an accelerometer and be randomised; follow-up rates $>75 \%$ of those randomised; $\geq 50 \%$ of those in iPOPP would complete week 1 and 2 intervention sessions; and a median score of $\geq 5 / 10$ across a four-item intervention acceptability and credibility questionnaire.

Results are number (\%) or median (inter quartile range (IQR)).

Results: Of 2326 people mailed, $1256(54 \%)$ responded and $695(30 \%)$ were eligible. After mailing study information to 425 eligible participants, 161 (38\%) agreed to participate, 159 ( $12 \%$ of those mailed) returned an accelerometer and were randomised, 7 withdrew, and $136(86 \%)$ returned a follow-up questionnaire. Of those randomised to iPOPP $82 \%$ completed week 1 and 2 intervention sessions; $32 \%$ had a face-to-face week 2 follow-up; $48 \%$ preferred postcard motivational prompts, $10 \%$ email, $22 \%$ text, and $20 \%$ had no preference. Median (IQR) acceptability and credibility scores were: "how logical is treatment?" 8 ( 3 , 9.8), "confidence in treatment success" $5.5(3,8)$, "would recommend treatment to friend" $7(3.3,9)$, and "treatment would be successful for another pain problem" $5(3,7.8) .152$ participants were mailed a follow-up accelerometer and $144(95 \%)$ were returned. $147(91 \%)$ baseline and $117(81 \%)$ follow-up accelerometers had useable data.

Conclusions: These data demonstrate the acceptability and credibility of the iPOPP intervention, and the feasibility of proposed trial processes. The effectiveness of iPOPP compared with usual care will be tested in a future main trial.

Acknowledgements: Funded by Arthritis Research UK (grant reference 20608). ELH, CJ, and CCG are part funded by the NIHR Collaborations for Leadership in Applied Health Research and Care West Midlands. The views expressed in this paper are those of the author(s) and not necessarily those of the NHS, the NIHR, or the Department of Health.

Disclosure of Interest: None declared

DOI: 10.1136/annrheumdis-2017-eular.2699

\section{SAT0522 SEARCHING FOR THE OPTIMAL TIMING FOR PREVENTIVE WEIGHT REDUCTION STRATEGIES FOR KNEE OSTEOARTHRITIS DEVELOPMENT}

J. Runhaar ${ }^{1}$, M. Landsmeer ${ }^{1}$, M. van Middelkoop ${ }^{1}$, S.M. Bierma-Zeinstra ${ }^{2}$ ${ }^{1}$ General Practice; ${ }^{2}$ General Practice and Orthopaedics, Erasmus University Medical Center Rotterdam, Rotterdam, Netherlands

Background: We previously showed that middle-aged women free of clinical knee osteoarthritis $(\mathrm{OA})$, but at high-risk for future OA development due to a BMI $\geq 27 \mathrm{~kg} / \mathrm{m}^{2}$, had a high prevalence of OA features on MRI [1]. Subjects with a steadily decrease in body weight over 30 months $(-9.0 \pm 7.2 \mathrm{~kg})$, did not show a significantly different progression of these features, compared to those without loss in body weight [2].

Objectives: To explore the effects of differences in body weight in the years prior to inclusion on the prevalence of knee OA on MRI at baseline, to discuss the optimal timing for preventive weight loss strategies for OA development.

Methods: Data from the PROOF study (ISRCTN 42823086) were used [3]. At baseline, women aged $50-60$, with a BMI $\geq 27 \mathrm{~kg} / \mathrm{m}^{2}$ were recruited. At inclusion, the women were free of clinical knee OA. At baseline, all participants filled-in a questionnaire for demographic data, including body weight at age 40 , and body weight and height were measured. BMI at 40 years and at baseline was calculated and classified into normal weight (BMI $<25 \mathrm{~kg} / \mathrm{m}^{2}$ ), overweight (BMI $>25$ and $<30 \mathrm{~kg} / \mathrm{m}^{2}$ ) and obesity $\left(\mathrm{BMI} \geq 30 \mathrm{~kg} / \mathrm{m}^{2}\right)$. MRl scans of both knees was made on a 1.5 Tesla scanner. All MRIs were scored using the semi-quantitative MRI
Osteoarthritis Knee Score (MOAKS) and MRI OA was defined in all knees was defined using published definitions [4]. Using logistic regression, the percentages of women with MRI OA, with unilateral MRI OA, bilateral MRI OA, and with $\geq 2$ affected compartments were compared, using the normal/overweight group as reference.

Results: 374 women had all baseline measurements available and were selected. At baseline, 127 women were overweight and 248 were obese. Mean age was $55.7 \pm 3.2$ years. Of the baseline obese women, $11 \%$ ( 26 women) reported normal weight, $52 \%$ (130 women) overweight and $37 \%$ (92 women) obesity at 40 years. Of the baseline overweight women, $39 \%$ (49 women) reported normal weight, $61 \%$ (77 women) overweight and 1 woman reported obesity at 40 years (see figure).

Baseline prevalence of MRI OA, of unilateral/bilateral MRI OA, and the percentage of women with $\geq 2$ affected compartments, out of both TF and both PF compartments, are presented in the table.

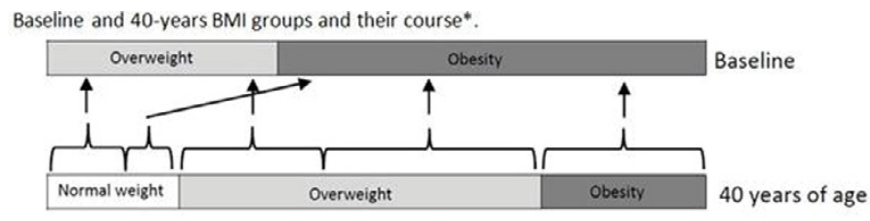

"the one overweight woman at baseline that reported obesity at 40 years was omitted for clarity reasons.

Prevalence of MRI OA for different subgroups by BMI course.

\begin{tabular}{|c|c|c|c|}
\hline BMI group at 40 years & BMI group at baseline & $\mathrm{N}^{*}$ & $\begin{array}{c}\text { Prevalence of MRI OA } \\
\text { overall (uni-/bilateral } / 2+\text { compartments) }\end{array}$ \\
\hline Obesity & Obesity & 92 & $44 \%^{\prime \prime}\left(25 \% " / 19 \%^{\prime \prime} / 23 \%^{\prime \prime}\right)$ \\
\hline Overweight & Obesity & 130 & $32 \%^{\prime \prime}\left(25 \%^{\prime \prime} / 7 \% / 9 \%\right)$ \\
\hline Normal weight & Obesity & 26 & $23 \%(15 \% / 8 \% / 12 \%)$ \\
\hline Overweight & Overweight & 77 & $27 \%(22 \% / 5 \% / 12 \%)$ \\
\hline Normal weight & Overweight & 49 & $16 \%(10 \% / 6 \% / 6 \%)$ \\
\hline
\end{tabular}

Conclusions: Women with higher body weight at 40 years showed higher prevalence of knee OA on MRI at the age of 56 . It is highly questionable whether $\mathrm{OA}$ related structural abnormalities seen on MRI are reversible. It is suggested that body weight reduction around the age of 40 might be much more effective for the prevention of future knee OA development than it would be at the age range of 50 to 60 years, where radiographic and clinical knee OA usually develops.

\section{References:}

[1] Landsmeer M, Runhaar J, et al. Reducing progression of knee OA features assessed by MRI in overweight and obese women: secondary outcomes of a preventive RCT. OA\&C, 2016;24:982-90.

[2] Landsmeer $M$, de Vos $B$, et al. Effect of weight change on progression of knee OA features assessed by MRI in high-risk overweight and obese women. OA\&C, 2016;24:S263-S264.

[3] Runhaar J, van Middelkoop M, et al. Prevention of knee osteoarthritis in overweight females: the first preventive randomized controlled trial in osteoarthritis. Am J Med. 2015;128(8):888-895.e4.

[4] Hunter D, Arden N, et al. Definition of osteoarthritis on MRI: results of a Delphi exercise. OA\&C, 2011;19(8):963-9.

Disclosure of Interest: None declared

DOI: 10.1136/annrheumdis-2017-eular.5795

\section{SAT0523 NO TREATMENT EFFECTS OF ORAL GLUCOSAMINE FOR SUBGROUPS OF KNEE AND HIP OSTEOARTHRITIS PATIENTS; AN INDIVIDUAL PATIENT DATA META-ANALYSIS FROM THE OA TRIAL BANK}

J. Runhaar $^{1}$, R. Rozendaal ${ }^{1}$, M. van Middelkoop ${ }^{1}$, J. Bijlsma ${ }^{2}$, M. Doherty ${ }^{2}$, K. Dziedzic $^{2}$, L. Lohmander ${ }^{2}$, T. McAlindon ${ }^{2}$, W. Zhang ${ }^{2}$, S. Bierma-Zeinstra ${ }^{2}$. ${ }^{1}$ General Practice, Erasmus University Medical Center Rotterdam; ${ }^{2} O A$ Trial Bank Steering Committee, Rotterdam, Netherlands

Background: The effectiveness of oral glucosamine for symptoms of osteoarthritis $(\mathrm{OA})$ is debated. Individual trials are not powered to show effects within subgroups of patients.

Objectives: To evaluate the effectiveness of oral glucosamine in clinical relevant subgroups of hip and knee OA patients based on pain severity, BMI, sex, structural abnormalities and inflammation, using individual patient data from published trials. Methods: A systematic search for published randomized controlled trials on the effectiveness of any oral glucosamine substance in patients with clinically or radiologically defined knee or hip OA was performed. Additionally, trail registries were searched for ongoing studies. All authors and institutions of all eligible studies were approached and asked to share the trial data. All shared trials were assessed for their risk of bias, using the criteria recommended by the Cochrane. Missing data for covariates and outcome measures were imputed, using multiple imputation methods, within each original study. Subgroup factors were dichotomized, based on consensus of the OA Trial Bank Steering Committee. A multilevel regression analysis was performed to estimate the magnitude of the effect of glucosamine over the control intervention in the different subgroups with the individuals nested within each study. Pain at short-term (3 months) 
and long-term (24 months) served as primary outcomes measure, function as secondary. Outcome measures measured on different scales were standardized to a $0-100$ scale to pool the data. All analyses were performed with and without stratifying for affected joint and type of glucosamine substance.

Results: Out of 21 eligible studies, six studies $(\mathrm{N}=1663)$ shared their trial data with the OA Trial Bank. Only one of these studies $(\mathrm{N}=40)$ was industry driven. All six studies had a low risk of bias, of which five trials (all not industry driven) compared glucosamine to placebo. These five studies represented $50 \%$ of the total number of randomized subjects in all published trials for this comparison. No main effects of glucosamine were found on pain or function at short-term (mean difference $0.3195 \% \mathrm{Cl}$ [-2.02 to 2.64$]$ and 1.56 [-0.56 to 3.69], respectively) and at long-term follow-up (0.98 [-1.76 to 3.73$]$ and 1.40 [-1.27 to 4.06$]$, respectively). Also, no significant interactions with treatment were found for subgroups based on pain severity (WOMAC pain $<70 \mathrm{vs.} \geq 70$ ), BMI $\left(<27 \mathrm{~kg} / \mathrm{m}^{2} \mathrm{vs} . \geq 27 \mathrm{~kg} / \mathrm{m}^{2}\right)$, sex (male vs. female) and structural abnormalities (KL-grade $0-2$ vs. 3-4), see Table. Stratification for knee OA patients only and for type of glucosamine did not result in any differences in the outcomes. No data was available to adequately form subgroups based on degree of inflammation.

\begin{tabular}{|c|c|c|c|c|c|c|}
\hline & & $\begin{array}{l}\text { All studies } \\
\text { (N=1394) }\end{array}$ & $\begin{array}{c}\text { Knee } 0 A \\
\text { only } \\
(\mathrm{N}=1172)\end{array}$ & $\begin{array}{l}\text { GH in knee } O A \\
(N=671)\end{array}$ & $\begin{array}{l}\text { GS in knee } \\
\text { and hip OA } \\
(\mathrm{N}=723)\end{array}$ & $\begin{array}{c}\text { GS in knee } O A \\
\quad(N=501)\end{array}$ \\
\hline \multirow{7}{*}{ 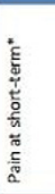 } & \multicolumn{6}{|c|}{ Estimated pooled differences and $95 \%$ confidence interval } \\
\hline & $\begin{array}{l}\text { Glucosamine vs } \\
\text { placebo }\end{array}$ & $\begin{array}{c}0.31 \\
(-2.02-2.64)\end{array}$ & $\begin{array}{c}0.53 \\
(-2.21-3.26)\end{array}$ & $\begin{array}{c}1.97 \\
(-1.14-5.09)\end{array}$ & $\begin{array}{c}-2.62 \\
(-6.03-0.79)\end{array}$ & $\begin{array}{c}-5.99 \\
(-11.50--0.48)\end{array}$ \\
\hline & \multicolumn{6}{|c|}{$p$-values for treatment-subgroup interactions } \\
\hline & Pain subgroup & 0.80 & 0.92 & 0.94 & 0.59 & 0.81 \\
\hline & BMI subgroup & 0.36 & 0.66 & 0.83 & 0.30 & 0.43 \\
\hline & Sex subgroup & 0.80 & 0.70 & 0.80 & 0.67 & 0.62 \\
\hline & KL subgroup & - & . & . & - & . \\
\hline \multirow{7}{*}{ 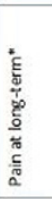 } & \multicolumn{6}{|c|}{ Estimated pooled differences and $95 \%$ confidence interval } \\
\hline & $\begin{array}{l}\text { Glucosamine vs } \\
\text { placebo }\end{array}$ & $\begin{array}{c}0.98 \\
(-1.76-3.73)\end{array}$ & $\begin{array}{c}0.19 \\
(-2.83-3.22)\end{array}$ & $\begin{array}{c}0.78 \\
(-4.33-5.89)\end{array}$ & $\begin{array}{c}1.22 \\
(-1.90-4.33)\end{array}$ & $\begin{array}{c}-0.38 \\
(-3.67-2.90)\end{array}$ \\
\hline & \multicolumn{6}{|c|}{$\rho$-values for treatment-subgroup interactions } \\
\hline & Pain subgroup & 0.26 & 0.28 & 0.42 & 0.44 & 0.86 \\
\hline & BMI subgroup & 0.55 & 0.10 & 0.51 & 0.72 & 0.10 \\
\hline & sex subgroup & 0.46 & 0.53 & 0.75 & 0.52 & 0.77 \\
\hline & KL subgroup & $\cdot$ & 0.40 & . & . & - \\
\hline \multirow{7}{*}{ 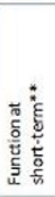 } & \multicolumn{6}{|c|}{ Estimated pooled differences and $95 \%$ confidence interval } \\
\hline & $\begin{array}{l}\text { Glucosamine vs } \\
\text { placebo }\end{array}$ & $\begin{array}{c}1.56 \\
(-0.56-3.69)\end{array}$ & $\begin{array}{c}1.57 \\
(-0.93-4.31)\end{array}$ & $\begin{array}{c}2.13 \\
(-0.82-5.09)\end{array}$ & $\begin{array}{c}0.74 \\
(-2.06-3.53)\end{array}$ & $\begin{array}{c}-1.38 \\
(-5.91-3.16)\end{array}$ \\
\hline & \multicolumn{6}{|c|}{$\rho$-values for treatment-subgroup interactions } \\
\hline & Pain subgroup & 0.46 & 0.32 & 0.38 & 0.97 & 0.90 \\
\hline & BMI subgroup & 0.92 & 0.87 & 1.00 & 0.83 & 0.45 \\
\hline & Sex subgroup & 0.55 & 0.37 & 0.23 & 0.49 & 0.79 \\
\hline & $\mathrm{KL}$ subgroup & - & - & . & - & . \\
\hline \multirow{7}{*}{ 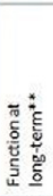 } & \multicolumn{6}{|c|}{ Estimated pooled differences and $95 \%$ confidence interval } \\
\hline & $\begin{array}{l}\text { Glucosamine vs } \\
\text { placebo }\end{array}$ & $\begin{array}{c}1.40 \\
(-1.27-4.06)\end{array}$ & $\begin{array}{c}0.63 \\
(-2.31-3.58)\end{array}$ & $\begin{array}{c}0.85 \\
(-4.43-6.13)\end{array}$ & $\begin{array}{c}2.02 \\
(-0.82-4.86)\end{array}$ & $\begin{array}{c}0.62 \\
(-2.29-3.52)\end{array}$ \\
\hline & \multicolumn{6}{|c|}{$p$-values for treatment-subgroup interactions } \\
\hline & Pain subgroup & 0.49 & 0.38 & 0.55 & 0.94 & 0.91 \\
\hline & BMI subgroup & 0.82 & 0.42 & 0.65 & 0.56 & 0.68 \\
\hline & Sex subgroup & 0.72 & 0.61 & 0.80 & 1.00 & 0.94 \\
\hline & KL subgroup & : & 0.77 & . & - & . \\
\hline \multicolumn{7}{|c|}{$\begin{array}{l}\text { "measured using WOMAC pain }(0-100) \text { and adjusted for age sex, BMI, WOMACpain at baseline and } \\
\text { study number. }{ }^{* x} \text { measured using WOMAC function }(0-100) \text { and adjusted for age sex, BMI, WOMAC } \\
\text { function at baseline and study number. Positive estimated pooled differences indicate a greater } \\
\text { reduction in the outcome in the glucosamine group compared to the place bo group. } G S=\text { glucosamine } \\
\text { sulphate; } G H=\text { glucosamine hydrochloride. }\end{array}$} \\
\hline
\end{tabular}

Conclusions: The majority of industry-led glucosamine studies for osteoarthritis did not wish to share data, challenging optimal use of available data. There is currently no evidence for the use of glucosamine for the treatment of hip or knee osteoarthritis and an absence of support for clinically relevant subgroups of $\mathrm{OA}$ patients according to baseline pain severity, BMI, sex, and structural abnormalities.

Disclosure of Interest: None declared

DOI: 10.1136/annrheumdis-2017-eular.5986

\section{SAT0524 UTILITY OF TOCILIZUMAB IN CLINICAL MANIFESTATIONS OF EROSIVE OSTEOARTHROSIS OF HANDS REGIONAL HOSPITAL ISSSTE PUEBLA, MÉXICO}

J.M. Sánchez Huerta ${ }^{1}$, J. Gálvez-Romero ${ }^{2}$, W. López-Rodriguez ${ }^{1}$, A. López ${ }^{3}$. ${ }^{1}$ Rheumatology; ${ }^{2}$ ISSSTE, Puebla, Puebla; ${ }^{3}$ UDLAP, Cholula, Puebla, Mexico

Background: Erosive osteoarthritis (EOA) is a form of severe involvement of osteoarthrosis in the hands, characterized by inflammation of the synovium of the proximal interphalangeal (PIF) and distal joints (DIF); the last ones are the most affected in a symmetrical manner. Inhibition of interleukin 6 (IL-6) in joints with osteoarthrosis helps to improve the production of the cartilaginous matrix and microfractures of articular cartilage.

Objectives: To know if the application of TCZ is useful for the control of the clinical manifestations of EOA of the hands.

Methods: Twenty-four patients with EOA were studied, 18 females and 6 males with ages ranging from 42 to 72 years, with an evolution time of 4 to 30 years. The application of TCZ was intravenous ( $8 \mathrm{mg} / \mathrm{kg}$ of body weight per month). Articular pain in the PIF and distal joints was evaluated by the visual analogue scale (VAS) (0 to 10) and joint pain (0 to 50 ), morning stiffness (0 to 10), and functional limitation (0-90) by the AUSCAN index.

Results: The VAS showed improvement of $30 \%$ ( $0 \%$ to $100 \%$ ). The AUSCAN index showed improved pain (16.2), morning stiffness (0.6) and functional limitation (17.5). Decreased ESR, CRP, and IL-6 levels less than 1.56 to 59.1 $\mathrm{pg} / \mathrm{ml}$.

Conclusions: IV Tocilizumab is useful for the control of the clinical manifestations of OAE of the hands. More precise studies are needed to evaluate the improvement of the cartilaginous matrix in EOA by TCZ.

Disclosure of Interest: None declared

DOI: 10.1136/annrheumdis-2017-eular.6483

\section{SAT0525 THE EFFICACY OF PELOID THERAPY IN MANAGEMENT OF HAND OSTEOARTHRITIS}

M. Aksoy Kasapoğlu ${ }^{1}$, L. Altan ${ }^{2}$, R. Eröksüz ${ }^{3}$, B. ÖkmenMetin ${ }^{1} .{ }^{1}$ Physical Medicine and Rehabilitation, University of Health Sciences Bursa Yüksek Ihtisas Training and Research Hospital; ${ }^{2}$ Physical Medicine and Rehabilitation, Uludağ University Medical Faculty; ${ }^{3}$ Ecology and Hydroclimatology, University of Health Sciences Bursa Yüksek Ihtisas Training and Research Hospital, Bursa, Turkey

Background: Hand osteoarthritis $(\mathrm{OA})$ is associated with pain, reduced grip strength, loss of range of motion (ROM), and joint stiffness, leading to impaired hand function and difficulty in performance of daily living activities. Various randomized controlled clinical trials were conducted to assess the efficacy and tolerability of mud-pack therapy in patients with knee OA. Data from these clinical trials support the beneficial effect of mud-pack therapy on pain, function, and quality of life in knee OA. However, to the best of our knowledge, in spite of its significant impact of on the activities of daily life, there is a lack of adequate randomized controlled studies on peloid therapy in management of osteoarthritis of the hand

Objectives: To investigate the effects of peloid therapy in the patients with hand $O A$ on pain, functional state, grip strength, and the quality of life

Methods: 63 patients aged between 35 and 75 years, who had been diagnosed with hand OA were included in the study. Patients were randomized into 2 groups with a random number table. Patients in Group $1(n=33)$ underwent peloid therapy over 2 weeks, 5 sessions a week, for a total of 10 sessions and home exercise program. Patients in Group 2 (control, $n=30$ ) received only the same home exercise program as in Group 1. Patients were evaluated just before, and 2 and 6 weeks after the start of the study with Visual Analogue Scale (VAS), Australian/Canadian Osteoarthritis Hand Index (AUSCAN) Health Assessment Questionnaire (HAQ), Hand Grip Strength (HGS), Pinch strength (PS).

Results: Statistically significant improvements were observed in all parameters assessed at week 2 and week 6 in the Group $1(p<0.05)$. Statistically significant differences were observed in HGS scores in the Group 2 at week 2, and in AUSCAN scores at week $6(p<0.05)$. Intergroup comparisons of the scores revealed significant differences between the peloid therapy group and control group in VAS, HAQ, AUSCAN, HGS and PS scores at week 2 and week 6 $(p<0,05)$.

Conclusions: This study demonstrates that peloid therapy is an effective and confident treatment modality in the management of symptomatic osteoarthritis of the hand and provides effective pain control and improvements in the hand functions, quality of life and grip strength

\section{References:}

[1] Zhang Y, Niu J, Kelly-Hayes M, Chaisson CE, Aliabadi P, Felson DT. Prevalence of symptomatic hand osteoarthritis and its impact on functional status among the elderly. Am J Epidemiol 2002;156:1021-7.

[2] Bellometti S, Cecchettin M, Galzigna L (1997) Mud-pack therapy in osteoarthrosis. Changes in serum levels of chondrocyte markers. Clin Chim Acta 268:101-106.

[3] Odabaș E, Turan M, Erdem H, Pay S, Gülec M, Karagülle MZ. The Effect of Mud Pack Treatment in Knee Osteoarthritis. Turk J Rheumatol 2009; 24: 72-6. Disclosure of Interest: None declared

DOI: 10.1136/annrheumdis-2017-eular.2310

\section{SAT0526 POSSIBILITY OF CARTILAGE REPAIR WITH PLATELET AUTOLOGOUS PLASMA (PAP)}

L.V. Khimion ${ }^{1}$, O.A. Burianov ${ }^{2}$, L.O. Smolina ${ }^{1}$, H. Havryliuk ${ }^{1}$, T. Omelchenko ${ }^{3}$. ${ }^{1}$ Department of Family Medicine, Shupyk National Medical Academy of

Postgraduate Education; ${ }^{2}$ Traumatology and Orthopedic Department;

${ }^{3}$ Traumatology and Orthopedic Department, Bogomolets National Medical University, Kiyv, Ukraine

Background: The investigations of the platelet-derived biologic agents in osteoarthritis treatment had shown promising but often controversial results.

Objectives: To study the efficacy (in clinic \& experiment) \& safety (in clinic) of the platelet autologous plasma (PAP) in cartilage repair and treatment of early knee OA.

Methods: The study was conducted at the Department of Family Medicine and Traumatology and Orthopedic Department and consisted of 2 parts: experimental (20 rabbits with the traumatic damage of the knee cartilages) and clinical (included 146 patients with diagnosed knee OA (radiological stage I-II). Rabbits 